\title{
REDES DE COOPERAÇÃO E ESTRATÉGIAS DE MARKETING NO MERCADO INTERNACIONAL: ENTENDENDO A ATUAÇÃO DE UM CONSÓRCIO DE EXPORTAÇÃO E DE UMA ASSOCIAÇÃO DE MICRO E PEQUENAS EMPRESAS EXPORTADORAS.
}

\author{
Breno de Paula Andrade Cruz
}

Deborah Moraes Zouain

\section{RESUMO}

O presente artigo tem como objetivo identificar quais são estratégias de marketing de um consórcio de exportação e de uma associação de micro e pequenas empresas no mercado internacional. Utilizandose o método Grounded Theory, analisam-se na perspectiva do marketing dois tipos de redes de cooperação: (i) consórcios de exportação e (ii) associação de pequenas empresas exportadoras. São encontradas na análise três categorias: grande categoria, categorias iniciais e categorias intermediárias. Nas categorias intermediárias encontram-se as variáveis do composto promocional (preço, praça, produto e promoção), sendo estas categorias influenciadas diretamente pelas categorias iniciais e pela grande categoria. A principal conclusão do artigo é que tanto o consórcio quanto a associação seguem uma linha semelhante de atuação na formulação das estratégias de marketing, mesmo com características jurídicas diferentes.

Palavras-chave: Estratégias de marketing. Composto promocional. Redes de cooperação.

\begin{abstract}
The purpose of this article is to identify the marketing strategies of an exporting consortium and an association of micro and small companies in the international market. Using the Grounded Theory method, two types of cooperation networks are analyzed under the marketing point of view: (i) export consortiums and (ii) association of small exporting companies. Three categories are found in this analysis: a major category, preliminary categories and intermediate categories. The intermediate categories cover the promotional marketing variables - price, marketplace, product and promotion. These categories are directly influenced by the preliminary categories and by the major category. The main conclusion this paper draws is that both the consortium and the association follow a similar line of performance in the design of marketing strategies, even with different legal characteristics.
\end{abstract}

Keywords: Marketing strategies. Promotional marketing. Cooperation networks. 


\section{INTRODUÇÃO}

A temática das exportações no Brasil tem assumido destaque na política econômica do país após o crescimento na participação de micro e pequenas empresas no mercado internacional. Várias são as estratégias de inserção no mercado internacional, dentre elas cabem ressaltar no âmbito das pequenas e micro empresas a formação de associações e consórcios de exportação. Essas duas estratégias de sobrevivência e de busca de competitividade permeiam o conceito de Redes de Cooperação.

A união de empresas em redes de cooperação geralmente está relacionada às vantagens obtidas no rateio de custos ou no aumento do poder de barganha junto aos fornecedores. Nessa relação, todos os envolvidos devem obter ganhos proporcionais ou igualitários (quando for o caso). De acordo com Verschoore (2004), no caso de pequenas empresas, as redes de cooperação assumem um papel importante no processo de competitividade.

Assim, na demarcação do conceito de redes de cooperação, neste artigo, utiliza-se o conceito de Rosenfeld (1997). Para o autor, redes de cooperação podem ser entendidas como atividades de negócios com caráter colaborativo em que geralmente pequenos grupos de firmas se unem no intuito de buscar maior competitividade (lucros) por meio de pesquisa e desenvolvimento de produtos, exportação ou aumento do poder de barganha perante diversos atores do processo.

Neste sentido, um consórcio de exportação e uma associação estariam vinculados ao conceito de redes de cooperação. Um consórcio de exportação, de acordo com Minervini (2001), é a união jurídica de micro e pequenas empresas de uma determinada região ou segmento que objetivam a inserção de seus produtos ou serviços no mercado externo. Já a demarcação do conceito de associação, neste artigo, está na definição de Timm e Silva $(2004$, p. 96): ter "personalidade jurídica [não sendo] formada por um contrato que tenha que ser modificado a cada entrada ou saída de novo membro". Este tipo de organização não desvirtua os objetivos econômicos das empresas.

Quanto aos consórcios de exportação, as duas classificações empíricas mais verificadas de consórcios no Brasil são: (1) promocional e (2) operacional. 0 primeiro se caracteriza como a união das empresas para promover seus produtos ou serviços no mercado externo, porém as vendas das empresas acontecem separadamente, aproximando-se do conceito de associação. Já no consórcio do tipo operacional, as empresas atuam juntas em todas as etapas do processo de exportação - desde o planejamento da produção até a entrega do produto final ao importador, o que permite ao consórcio que o preço de venda não seja calculado apenas em cima dos custos de produção e distribuição.

Ao comparar as estratégias de marketing adotadas por um consórcio de exportação e uma pequena exportadora do Pólo de Moda Íntima de Nova Friburgo, Cruz (2004) apresenta as principais vantagens mercadológicas de um consórcio de exportação: redução do efeito de sazonalidade do segmento; ganhos de escala com fornecedores; rateio entre as empresas de custos relativos à pesquisa de marketing no mercado internacional e participação em eventos internacionais. Pereira (2004) ao analisar, na perspectiva do marketing, uma rede de cooperação entre empresários do segmento de materiais de construção no Rio Grande do Sul, evidenciou as principais vantagens obtidas por este grupo de empresas. Dentre elas, estão: (i) o marketing compartilhado - rateio de custos, inserção em mídia televisiva e padronização 
Redes de cooperação e estratégias de marketing no mercado internacional: entendendo a atuação de um consórcio de exportação e de uma associação de micro e pequenas empresas exportadoras.

das fachadas das lojas; (ii) formação de uma marca; (iii) negociação com fornecedores; e, (iv) capacitação empresarial.

Dado o recente contexto da cooperação no Brasil e o objetivo do Congresso Redes de Cooperação Brasil, que discute esta temática, tem-se como problema de pesquisa a seguinte questão: quais são estratégias de marketing de um consórcio de exportação e de uma associação de micro e pequenas empresas no mercado internacional? Desta forma, o objetivo geral desta investigação é identificar quais são estratégias de marketing de um consórcio de exportação e de uma associação de micro e pequenas empresas no mercado internacional. Como objetivos específicos procura-se: (a) identificar as variáveis que influenciam a formulação das estratégias tanto do consórcio como da associação e (b) entender quais itens do composto promocional são importantes na elaboração das estratégias de marketing no mercado externo em redes de cooperação.

Esta investigação, de caráter qualitativo, é delimitada a partir de questões que emergiram a partir da coleta de dados da pesquisa de campo que utilizou do método Grounded Theory. Assim, aspectos relacionados à legislação exportadora, tratados internacionais, barreiras aduaneiras ou variação cambial, embora importantes, não serão discutidos neste artigo pelo fato de não terem relevância para este estudo específico.

No que diz respeito à relevância deste artigo, três aspectos devem ser destacados aqui: (i) a relação das redes de cooperação com o empreendedorismo, (ii) os arranjos produtivos locais e (iii) os aspectos de desenvolvimento econômico que estes tipos de ações trazem para uma região. Paradoxalmente, estes aspectos sustentam, em muitas situações, as pesquisas acadêmicas que utilizam o instrumento de estudo de caso, pois conforme alguns estudos, o empreendedorismo e os arranjos produtivos locais são considerados elementos importantes na geração de trabalho e renda, dando dinâmica à economia regional e nacional. Já do ponto de vista teórico, este trabalho se torna relevante pelo fato de analisar atuação de um consórcio e uma associação de pequenas empresas.

Este primeiro item do trabalho fez uma breve contextualização da temática das redes de cooperação, consórcios de exportação e associações interfirmas, além de apresentar o problema de pesquisa, os objetivos geral e específicos e a relevância teórica e prática desta pesquisa. 0 próximo item apresenta a fundamentação teórica deste artigo baseando-se nos elementos do composto promocional. A metodologia do trabalho é apresentada no item 3, sendo seguida pelos resultados da pesquisa (item 4) que estrutura as categorias e subcategorias encontradas na pesquisa de campo. 0 item 5 tece algumas considerações a respeito dos resultados encontrados. 0 item 6 apresenta as limitações e as sugestões para próximas investigações.

\section{FUNDAMENTAÇÃO TEÓRICA}

A fundamentação teórica desta investigação tem sua base consolidada na perspectiva do marketing e foi construída a partir das quatro categorias intermediárias encontradas a partir do método de pesquisa utilizado neste trabalho: a Grounded Theory. Estas quatro categorias encontradas estão relacionadas ao composto promocional na teoria de marketing: produto, promoção, preço e praça. Embora estas variáveis sejam discutidas em muitos livros técnicos e artigos acadêmicos, elas são importantes no contexto desta pesquisa, pois contribuem no entendimento da atuação de marketing dos consórcios analisados neste trabalho. Por ser uma temática pouco abordada em pesquisas acadêmicas em marketing, pouca bibliografia existe sobre a atuação de consórcios de exportação. 0 artigo de Cavusgil e Zou (1994) auxilia na base 
teórica deste estudo ao analisar os 4 Ps na atuação de empresas exportadoras de cinco estados americanos.

No estudo realizado pelos pesquisadores, 79 empresas de 16 segmentos diferentes participaram da amostra. No total de 202 observações envolvendo os atores gerenciais que participavam ativamente do processo de exportação destas firmas, Cavusgil e Zou constataram, por meio do método de Análise Fatorial, que as estratégias de marketing nas exportações das empresas dependiam de fatores relacionados ao mercado interno e ao mercado externo. Ao detalharem os fatores que influenciam o desempenho exportador de marketing, os autores destacam a importância de (1) adaptação do produto; (2) adaptação da promoção; (3) suporte do distribuidor externo (praça); e (4) competitividade do preço, destas variáveis no processo.

É necessário fazer a distinção de alguns conceitos e delimitá-los neste trabalho. Neste sentido, entende-se por desempenho exportador o resultado final de uma organização no processo de exportação de produtos ou serviços, podendo este resultado ser influenciado pelas estratégias adotadas pelas empresas ou pelas economias dos países importadores ou exportadores. Da mesma forma, apresenta-se a delimitação do conceito de export marketing strategy neste estudo. Assim, tem-se:

Export marketing strategy is the means by which a firm responds to the interplay of internal and external forces to meet the objectives of the export venture. It envolves all aspects of the conventional marketing plan, including product, promotion, pricing, and distribution (Cavusgil e Zou, 1994, p. 4).

A necessidade de focar as ações para o mercado internacional e ter Orientação para Mercado Externo (OME) contribui na consolidação de resultados positivos para as empresas exportadoras no comércio internacional. 0 conceito de OME, que é trabalhado por Cadogan et al (1999), e abordado no contexto brasileiro por Macera e Urdan (2004), ressalta a importância de direcionar as ações das empresas exportadoras para o mercado externo. Logo, constata-se que a organização deve planejar sua entrada no mercado externo e não vê-lo apenas como a extensão do mercado interno.

O conhecimento de marketing no mercado externo é uma variável condicionante no desempenho exportador. No caso de empresas brasileiras de médio e grande porte, Klotzle e Cairez (2004) analisaram quantitativamente o desempenho exportador destas empresas e perceberam que os exportadores consideram como variável mais importante a experiência no mercado internacional. Entretanto, essa experiência não está intrínseca ao planejamento ou pesquisa de marketing no mercado internacional.

O estudo de Cruz e Zouain (2006) encontrou, a partir do mesmo método de pesquisa a utilizado neste artigo, quatro variáveis de marketing que influenciam as estratégias de marketing de consórcios de exportação brasileiros no segmento de moda praia e moda íntima, quais sejam: produto, preço, promoção e praça. Estas variáveis foram classificadas como categorias intermediárias e sua composição é influenciada por categorias iniciais (específicas de cada variável) e por grandes categorias (características específicas da atuação de um consórcio de exportação).

A seguir é discutida a importância de produto, promoção, preço e praça no desempenho exportador de organizações que atuam no mercado internacional. Apesar de serem apresentados separadamente, há uma necessidade de abordá-los de forma sistêmica, conforme discute Wind e Robertson (1983). Sempre que possível, dada a escassez de 
Redes de cooperação e estratégias de marketing no mercado internacional: entendendo a atuação de um consórcio de exportação e de uma associação de micro e pequenas empresas exportadoras.

abordagem da temática, buscar-se-á fazer uma contextualização do tópico com os consórcios de exportação.

\section{Produto}

0 produto a ser comercializado no mercado internacional deve possuir algumas características que o façam, na maioria das vezes, distinto. Cavusgil e Zou (1994) destacam algumas características que um produto deve possuir - simultaneamente ou não - para obter um desempenho satisfatório no processo de exportação. São elas: (1) ser único - não existir produtos similares que desempenhem uma função parecida; (2) ser novo ou inovar acrescentando características não existentes em produtos similares ou concorrentes; (3) transmitir características de uma cultura específica; (4) possuir nível tecnológico satisfatório, atendendo a alguns padrões técnicos dos países importadores; e (5) o mercado exportador do produto ser competitivo por natureza.

No segmento de moda praia, por exemplo, é difícil concorrer com a China, que é extremamente eficiente na padronização dos produtos e, conseqüentemente, no preço. Desta forma, a estratégia utilizada por pequenas empresas exportadoras deste segmento, e por consórcios de exportação, é a customização das peças (CRUZ e ZOUAIN, 2005a). Este fenômeno de competição do setor têxtil entre Brasil e China exemplifica dois aspectos citados anteriormente por Cavusgil e Zou: características específicas de uma cultura (no caso do Brasil, a customização das peças por meio da utilização de características nacionais); e mercado exportador competitivo por natureza (China, que dispõe de mão-de-obra barata).

Aaby e Slater (1989) destacam que a descoberta de atributos únicos dos produtos e a tecnologia não são condições únicas para o sucesso do produto no mercado internacional, mesmo que muitas empresas, desde a década de 80, estejam acelerando a introdução de produtos pioneiros no mercado (Harrigan, 1987). Num estudo quantitativo que envolveu empresas de Brasil, Estados Unidos, Canadá e Europa, Aaby e Slater constataram que o desempenho do produto tem forte dependência da seleção prévia dos mercados importadores. Assim, no processo de exportação de um produto, diversas variáveis são levadas em consideração, e não apenas características técnicas ou tecnológicas.

O estudo realizado por Macadar (2004) a partir de uma associação de empresas moveleiras exportadoras no estado do Rio Grande do Sul revela que o design dos móveis exportados é determinado pelos importadores. Mais especificamente, o design e o marketing dos produtos sao realizados pela empresa contratante, o que impossibilita ganhos maiores na comercialização.

\section{Promoção}

A promoção no processo de exportação é uma variável importante no contato com o importador. A promoção não se caracteriza apenas por aspectos relacionados à propaganda do produto ou serviço, apesar de importante. 0 contato físico com o importador é extremamente necessário para a promoção de um produto. Conforme analisou Cruz (2004), a participação em feiras e missões internacionais - o contato físico com o cliente - contribuiu positivamente tanto para uma pequena empresa exportadora quanto para um consórcio de exportação em suas atuações no mercado externo. 0 autor verificou que as duas organizações consideraram esse contato extremamente importante para o desenvolvimento de relações com os importadores.

Além disso, Cavusgil e Zou (1994) constataram quantitativamente em seus estudos que a 
peculiaridade do produto, a experiência da firma com o produto e a experiência dos consumidores com a marca são características que afetam positivamente o desempenho exportador de uma empresa. De acordo com os autores, estas características devem ser trabalhadas em conjunto no processo de divulgação de um produto.

No que diz respeito à divulgação dos produtos ou serviços aos clientes, as empresas exportadoras devem ter a disponibilidade de mídia (Cavusgil e Zou, 1994), ou seja, espaços em jornais e revistas especializadas. Isso implica em questões relacionadas à propaganda ou publicidade da empresa. Aaby e Slater (1989) destacam que a ênfase em tais instrumentos é relevante para o aumento das vendas. Cruz (2004) apresenta empiricamente tais aspectos ao descrever a força da marca de um consórcio brasileiro no mercado internacional por meio da sua publicidade em um dos maiores jornais de moda do mundo.

Missões e feiras internacionais também são alvos no processo de promoção dos produtos das associações. No caso da associação de moveis estudada por Macadar (2004) a estratégia utilizada pelo segmento, além de folders de divulgação e websites, é o showroom - exposição de móveis aos clientes.

\section{Preço}

0 preço de um produto ou serviço está condicionado à concorrência, ao ambiente, aos procedimentos logísticos, aos custos de produção, dentre outros. A precificação de um produto no mercado internacional depende da estratégia da empresa, que pode ser de sobrevivência, por exemplo. As duas formas de precificação relevantes neste estudo são: (a) com base nos custos de produção e distribuição e (b) com base na criação de valor por meio de características diferenciais. Para tornar o preço competitivo, Aaby e Slater (1989) destacam que descontos ou formas de pagamento diferenciadas podem ser recursos para tornar o preço mais atraente. Mas essa estratégia deve ser usada somente quando o produto é padronizado e não possui outros diferenciais competitivos - o que não acontece com os consórcios aqui analisados.

O preço do produto no mercado internacional é influenciado também por fatores internos, por exemplo, matéria-prima, mão-de-obra e localização geográfica. Cavusgil e Zou (1994) atribuíram à orientação tecnológica da indústria o único fator determinante no preço, sendo que o engajamento da empresa e a competitividade do mercado não foram variáveis significativas na amostra estudada. Entretanto, alguns estudos empíricos mostram que variáveis como impostos de importação, tratados comerciais ou atravessadores também influenciam o preço final do produto. Cruz e Zouain (2005b) identificam empiricamente que o tipo de consórcio (promocional ou operacional) influência o preço de venda de um produto.

Ao analisar a formação do preço no mercado interno e externo de empresas que compõem um consórcio de exportação no segmento de calçados em Santa Catarina, Ramos et al (2005) constaram que não existiu diferença de precificação para os diferentes mercados, uma vez que as empresas se utilizavam do markup para definir o preço de venda nos dois mercados. Os autores justificaram tal verificação empírica pelo fato de as empresas não se encontrarem ainda num estágio inicial de marketing global. Já Cruz e Zouain (2005), ao analisarem empiricamente o processo de precificação de dois consórcios, argumentam que o tipo de consórcio - promocional ou operacional - é uma variável que também interfere no preço dos produtos.

A motivação inicial das empresas em participarem da rede foi a possibilidade de reduzir 
Redes de cooperação e estratégias de marketing no mercado internacional: entendendo a atuação de um consórcio de exportação e de uma associação de micro e pequenas empresas exportadoras.

custos. Assim como nos consórcios de exportação, a grande vantagem na variável preço é a diminuição de custos de produção e comercilização, além, é claro, do rateamento dos custos burocráticos de exportação (MACADAR, 2004), tornando o produto mais competitivo quando analisado na perspectiva do preço.

\section{Praça}

A escolha dos mercados em que as empresas irão atuar é extremamente importante para um desempenho satisfatório. Não é a fluência em um idioma ou a proximidade física que contribuirá na atuação de uma organização no mercado externo. Na distribuição dos produtos, outras características devem ser consideradas. Cavusgil e Zou (1994) apresentam três características essenciais para o sucesso de distribuição de um produto: (a) mercado exportador competitivo; (b) orientação tecnológica da indústria; e (c) engajamento da empresa.

A decisão de atuar em determinados mercados contribui para algumas características relacionadas à venda e à assistência técnica de alguns produtos. Os autores consideram que a escolha do mercado auxilia na força de vendas, no conhecimento de marketing e no suporte promocional no mercado internacional. Manter representantes comerciais no mercado internacional é importante na distribuição dos produtos e na proximidade com o cliente final, o que implica maior confiança para estes últimos.

De acordo com Cruz (2004), o planejamento da escolha dos mercados em que um consórcio deve atuar influência no planejamento do produto, na elaboração das estratégias de promoção, no preço e também na participação em feiras e missões internacionais. Entretanto, conforme apresenta Ramos et al (2005), algumas empresas que compõem um consórcio de exportação ainda não adotam estratégias diferenciadas para países ou regiões importadoras, mantendo uma postura global. Aaby e Slater (1989) reiteram que a definição dos mercados é essencial para o desempenho do produto. Os países importadores também influenciam nas ações de uma associação. A definição da praça influencia as variáveis anteriores.

\section{METODOLOGIA}

A investigação realizada neste estudo tem caráter qualitativo e, portanto, utiliza os instrumentos que compõem a pesquisa qualitativa em administração. Foram analisados um consórcio de exportação do segmento de moda praia e uma associação de pequenas empresas exportadoras do segmento de móveis. 0 método de pesquisa utilizado foi o Grounded Theory, pois não existiam hipóteses preconcebidas e, ao mesmo tempo, pouca teoria a respeito de consórcios de exportação e associações de pequenas empresas e suas atuações na perspectiva do marketing.

A escolha pela pesquisa qualitativa se deu pelo fato desta temática ainda ser relativamente pouco abordada nas investigações acadêmicas em administração e marketing. Além disso, a pesquisa qualitativa possibilita o surgimento de insights e especulações de um determinado contexto ou fenômeno, além da riqueza dos dados gerados na pesquisa de campo (VIEIRA, 2004).

A Grounded Theory é definida por Goulding (2001) como uma teoria desenvolvida que é baseada em dados sistematicamente reunidos e analisados, envolvendo o processo de pesquisa que é produto da contínua inter-relação de análise e coleta de dados. A utilização deste método neste artigo se dá pelo fato de existirem diferenças estruturais entre uma empresa e um consórcio de exportação. Logo, a teoria e as constatações empíricas existentes 
para uma empresa (independentemente do porte) podem não se adequar à dinâmica dos consórcios.

Neste sentido, dois tipos de estruturas foram escolhidas para este estudo: um consórcio de exportação e uma associação de pequenas empresas. No que diz respeito ao desenho da pesquisa, esta tem um corte seccional com perspectiva longitudinal ${ }^{1}$, pois resgata informações de outros períodos que contribuem para o entendimento do momento atual. Quanto à coleta de dados na entrevista em profundidade ${ }^{2}$, o instrumento utilizado foi um roteiro de entrevista semi-estruturado, pré-testado com dois pesquisadores da área e dois atores gerenciais de um consórcio. Este roteiro teve como objetivo possibilitar que temas importantes que não se encontravam na pesquisa fossem relatados pelos pesquisados. Estes últimos foram escolhidos intencionalmente, obedecendo à noção de que era necessário entrevistar o membro do consórcio/associação que estava mais inteirado da atuação da organização, não importando se ele era o presidente, o diretor de marketing ou o secretário executivo.

A utilização da Grounded Theory nesta investigação é justificada pelo fato de se buscar uma teoria sobre um contexto ou fenômeno que se está investigando a partir de dados coletados de uma realidade, sem existir a hipótese preconcebida de um fenômeno (VERGARA, 2005). Ademais, este método não objetiva a generalização das análises construídas a partir dos dados. A partir da sistematização do uso da Grounded Theory proposta por Vergara (2005, p. 102-103), apresentam-se a seguir os passos da pesquisa:

i. Definição do problema de pesquisa: quais são estratégias de marketing de um consórcio de exportação e de uma associação de micro e pequenas empresas no mercado internacional;

ii. Seleção (intencional) do consórcio e da associação a serem estudados;

iii. Seleção dos sujeitos para a realização das entrevistas;

iv. Inicialização do trabalho de campo e os registros referentes às entrevistas;

v. Identificação dos conceitos emergentes (diferenciação, qualidade, etc.) e agrupamento dos conceitos similares em categorias;

vi. Refinamento das categorias e integração dos resultados;

vii. Resgate do problema que deu origem à investigação;

viii. Validação da teoria por meio da checagem dos resultados com os entrevistados;

ix. Comparação da teoria gerada sobre consórcios na perspectiva do marketing com outros estudos, destacando as diferenças e as contribuições;

x. Conclusão.

\footnotetext{
${ }^{1}$ De acordo com Vieira (2004, p. 21) o corte seccional com perspectiva longitudinal se caracteriza pela coleta de dados em um determinado momento, mas que resgata informações de outros momentos passados. Os dados coletados do passado servem para contextualizar o momento atual da coleta de dados pois o foco está no fenômeno presente.
}

2 As entrevistas foram gravadas com a autorização prévia de cada entrevistado. 
Redes de cooperação e estratégias de marketing no mercado internacional: entendendo a atuação de um consórcio de exportação e de uma associação de micro e pequenas empresas exportadoras.

Esta seção apresentou os procedimentos metodológicos desta investigação. No próximo item são apresentados os resultados agregados da pesquisa de campo e as categorias encontradas a partir da utilização da Grounded Theory.

\section{RESULTADOS}

Este item do trabalho apresenta os resultados obtidos a partir da pesquisa de campo com os três consórcios de exportação do segmento de moda praia. De acordo com a utilização do método Grounded Theory, foi encontrada uma grande categoria que caracteriza a atuação de um consórcio de exportação: conhecimento de marketing no mercado externo. Já as categorias intermediárias estão relacionadas ao composto promocional: preço, promoção, produto e praça. As categorias iniciais são aquelas que estão presentes na atuação específica dos consórcios no segmento de moda praia. Os três níveis de categorias foram obtidos por meio da interpretação e análise das entrevistas em profundidade com os atores gerenciais dos consórcios de exportação. A figura 1 ilustra tais informações.

Figura 1: Categorias encontradas a partir da pesquisa de campo

\begin{tabular}{|c|c|c|}
\hline & $\begin{array}{c}\text { Categorias } \\
\text { Intermediárias }\end{array}$ & Categorias Iniciais \\
\hline $\begin{array}{l}\text { Grande } \\
\text { Categoria }\end{array}$ & Produto & $\begin{array}{l}\text { Qualidade } \\
\text { Diferenciaça } \\
\text { Localiaça Gro Grogrifica no } \\
\text { Brasil }\end{array}$ \\
\hline \multirow{3}{*}{$\begin{array}{l}\text { Conherimento de } \\
\text { Marketing no } \\
\text { Mercado } \\
\text { Intemadional }\end{array}$} & Promoção & 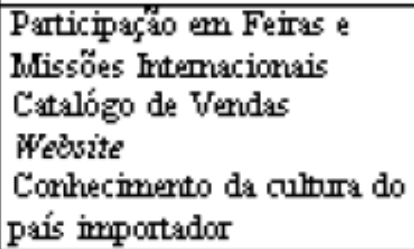 \\
\hline & Preço & $\begin{array}{l}\text { Teqnologia/Qualidade } \\
\text { Pesquisa de Marketing no } \\
\text { mercado irternacional }\end{array}$ \\
\hline & Praça & $\begin{array}{l}\text { Feiras e Missóes } \\
\text { Irternacionais } \\
\text { Representantes comerciais } \\
\text { Contatos pelo Website }\end{array}$ \\
\hline
\end{tabular}

Esta figura apresentou as categorias encontradas na atuação de um consórcio de exportação e de uma associação de pequenas empresas exportadoras. 0 que se percebe, inicialmente, a partir de sua visualização, é que os elementos do composto promocional (categorias intermediárias) são formados por características específicas no que diz respeito às estratégias de marketing destes dois tipos de redes interorganizacionais. Ao mesmo tempo, os elementos do composto promocional recebem influências de uma grande categoria: conhecimento de marketing do mercado externo.

Esta grande categoria emerge do contexto das organizações pesquisadas neste artigo, quais sejam: Conhecimento de características gerais do mercado importador; Pesquisa de marketing coletiva; e Participação em eventos internacionais. Constata-se que estas características, que compõem a grande categoria conhecimento de marketing no mercado externo, influenciam, assim, o composto promocional. Discutindo-se cada uma, tem-se: 
Conhecimento de características gerais do mercado importador - entender as características do mercado importador é importante na atuação do marketing de qualquer organização exportadora. Este conhecimento envolve o entendimento da cultura do país ou região importadora, o conhecimento da legislação e dos trâmites burocráticos e até o contato com possíveis representantes comerciais e distribuidores. De acordo com os representantes de cada instituição, é necessário entender o mercado externo de forma sistêmica, buscando a profissionalização de suas ações de marketing por meio do levantamento sistemático de informações do mercado.

Pesquisa de marketing coletiva - o levantamento das informações no mercado externo geralmente é onerosa. Por isso, uma das características da atuação entre firmas é a consecução da mesma em conjunto pelas empresas. A partir do momento que as empresas buscam informações de um mesmo segmento no exterior, elas acabam por direcionar suas ações para este mercado. Essa pesquisa coletiva, além de contribuir para o desempenho satisfatório do consórcio e da associação no exterior, contribui também para a atuação individual das empresas no mercado interno (ganham know-how).

Participação em eventos internacionais - finalizando a grande categoria Conhecimento de marketing no mercado externo, verifica-se que a participação em eventos internacionais é extremamente importante para que o consórcio melhore seu desempenho. A presença física contribui (i) para que se adeque à oferta do produto às necessidades do cliente e (ii) para o contato com o importador. No caso da associação estudada neste artigo, por exemplo, o "estar presente" em feiras de móveis é extremamente importante na construção da confiança do importador para com o exportador.

Os elementos do composto promocional, como categorias intermediárias, não serão descrito nesta seção, uma vez que estes já foram discutidos na fundamentação teórica. Com base nestas informações provenientes da pesquisa de campo e, consequentemente, da construção das categorias intermediárias, é que se apresentam as categorias iniciais. São elas:

Tecnologia/Qualidade - A tecnologia a que se referem os entrevistados diz respeito à qualidade do produto, padrões técnicos e sua aceitação no mercado externo. Por exemplo, atender aos padrões mínimos de exigências. Alta tecnologia não está relacionada à diferenciação dos produtos. No caso do consórcio do segmento de moda praia e moda íntima, o trabalho artesanal nas peças é totalmente artístico e sem uso de altas tecnologias. Já na associação do segmento de móveis, algumas exigências técnicas faz com que as empresas utilizem de ferramental tecnológico.

Localização geográfica no Brasil - 0 fato de as organizações estudadas se encontrarem em um pólo específico de produção, apresenta contribuições diversas. As principais contribuições estão relacionadas ao acesso à matéria-prima e mão-de-obra já qualificada; à tendência daquela região em produzir produtos de um mesmo setor e receber incentivos de ordem regional ou estadual; e à facilidade de empresas do mesmo setor cooperarem entre si para ganhos de escala, por exemplo.

Participação em feiras e missões - A participação em feiras e missões internacionais é extremamente importante para o contato com o cliente e para a exposição dos produtos aos possíveis importadores. As feiras internacionais são eventos de um segmento específico, enquanto que as missões internacionais são ações da Apex que visam à prospecção de mercado de diversos segmentos (simultaneamente) para divulgar a marca Brasil. Estar presente nos eventos ou até mesmo abrir um showroom, como é o caso da associação 
Redes de cooperação e estratégias de marketing no mercado internacional: entendendo a atuação de um consórcio de exportação e de uma associação de micro e pequenas empresas exportadoras.

estudada, contribui na efetivação da confiança do importador com o exportador.

Catálogo de vendas - Essa é a forma mais usual de apresentar os produtos aos importadores. Os catálogos de vendas dos consórcios são materiais de divulgação com qualidade, fotos estéticas e com alta resolução. No caso do consórcio de moda praia, explora-se o lado da 'brasileiridade' dos produtos e a sensualidade da mulher brasileira.

Website - A forma mais dinâmica e menos onerosa de apresentar os produtos aos importadores atualmente é pelo website. Este mecanismo serve como um catálogo eletrônico acessível de qualquer lugar do mundo, e, principalmente, para o contato do importador/representante com as organizações. Compradores interessados em adquirir os produtos ou pessoas que residem no exterior e que querem se tornar representantes podem fazer o primeiro contato pelo website.

Conhecimento da cultura do país importador - Conhecer as diferenças culturais dos países importadores é importante para que não se cometam erros culturais. Este conhecimento pode ser obtido por meio de uma pesquisa de mercado ou pela vivência de um ou mais membros das organizações em outros países.

Rateio dos custos - Uma das características presentes no processo de exportação de redes é o rateio dos custos entre as empresas que participam da estrutura interorganizacional. Essa característica é ressaltada pelos entrevistados, uma vez que estes consideram que uma pequena empresa arcar com custos referentes à pesquisa de marketing no mercado externo e a participação em eventos internacionais é inviável financeiramente.

Pesquisa de marketing internacional - Atuar no mercado internacional sem uma prévia pesquisa de marketing pode acarretar resultados positivos ou negativos, o que indica a incerteza no desempenho. 0 consórcio surgiu a partir da união de empresas que ainda não exportavam e que começaram a exportar após a pesquisa de marketing no mercado internacional. Já a associação começou a exportar antes de fazer uma pesquisa no mercado externo. Entretanto, hoje suas ações são direcionadas a partir de sistemáticas pesquisas de mercado.

Representantes comerciais - Ter representantes comerciais nos países importadores contribui significativamente para o aumento da participação dos grupos nestes mercados. Os representantes podem ser pessoas físicas ou jurídicas. No caso do consórcio, a maioria dos seus representantes é de pessoas jurídicas de grande porte, o que contribui para maior inserção dos produtos em grandes lojas de departamentos nos países importadores. A associação também possui representantes comerciais, alguns deles até mesmo no Brasil. Estes são responsáveis também por convidarem clientes a visitar as instalações das fábricas no Brasil.

\section{CONSIDERAÇõES FINAIS}

Quando foi proposto o problema de pesquisa desta investigação, procurou-se verificar qualitativamente quais seriam as variáveis que poderiam influenciar as estratégias de marketing de um consórcio de exportação e de uma associação de empresas exportadoras. A partir da utilização do método Grounded Theory, três categorias de análise neste artigo foram encontradas: (i) categorias iniciais, (ii) categorias intermediárias e (iii) grandes categorias.

Pode-se entender que as categorias iniciais e intermediárias estão, respectivamente, hierarquicamente subordinadas às grandes categorias. Ou seja, Os elementos do composto 
promocional (categorias intermediárias) no consórcio de exportação e na associação de empresas dependem do conhecimento de marketing do mercado externo. Da mesma forma, o composto promocional recebe influência das categorias iniciais.

$\mathrm{Na}$ análise do produto, neste estudo, verificou-se que as características do produto presentes na teoria foram encontradas nas verificações empíricas desta pesquisa. As principais características encontradas foram: a qualidade, a diferenciação e a localização geográfica do grupo dentro de uma região com vocação para a produção de um determinado segmento.

A variável promoção recebe grande importância nas estratégias de marketing das organizações aqui analisadas. Basicamente, as estratégias de promoção dos produtos estão consolidadas na busca da confiança do importador no exportador. Ou seja, a participação em feiras e missões internacionais contribuem na consolidação desta importante variável no processo de vendas. Com relação aos meios utilizados para divulgação dos produtos, além das feiras e missões internacionais, encontram-se os websites, os catálogos de vendas, os desfiles e showrooms.

No que diz respeito ao preço dos produtos, há uma divergência entre as organizações utilizadas neste trabalho. Enquanto a associação apenas faz o contato entre o importador e as empresas, no consórcio quem precifica as peças é a própria organização. Ou seja, o consórcio, por trabalhar com a diferenciação do produto e agregação de valor ao mesmo, construindo o processo de precificação do produto por meio de variáveis que vão além dos custos de produção e comercialização. Já a associação, fica responsável apenas pelo contato com os clientes, sendo que o processo de precificação fica por conta de cada empresa.

Quando se analisou a praça/distribuição, verificou-se a importância da participação em eventos internacionais e a necessidade de ser ter representantes comerciais nos países importadores. Além disso, uma nova forma de distribuição e contato aparece no contexto destas organizações: o contato e as vendas por meio do website. Além disso, percebe-se que há uma necessidade de focar os mercados em que se pretende atuar. Isso acontece por dois motivos especiais: padrões técnicos e diferenças culturais. 0 consórcio atua somente na Europa, Argentina e Chile. Já a associação, atua somente nos EUA, uma vez que considera ser este país um mercado onde o consumo é muito grande - "é a menina dos olhos de qualquer exportador".

Mediante os dados apresentados neste trabalho, como parte final da utilização da Grounded Theory, as categorias foram apresentadas aos entrevistados com o objetivo de confrontar as suas perspectivas práticas com as perspectivas teóricas que surgiram a partir da análise e interpretação dos dados coletados na pesquisa de campo deste estudo. Os entrevistados, sem prévio conhecimento de que aquelas categorias foram construídas com base em seus discursos sobre a atuação de suas respectivas redes, analisaram-nas e constataram que as mesmas contribuem no entendimento da atuação dos consórcios na perspectiva do marketing. Logo, a teoria apresentada neste estudo representa a realidade das instituições aqui analisadas.

A principal conclusão que se chega a partir da análise de diferentes redes interorganizacionais neste estudo é que a forma de atuação no mercado externo é semelhante. Logo, a forma jurídica - consórcio ou associação - não se configura como variável determinante no processo de exportação de pequenas empresas brasileiras, uma vez que tais redes se destacam em sues respectivos segmentos. Embora sejam de segmentos diferentes (móveis e moda praia), contatou-se neste artigo que suas estratégias de marketing seguem uma linha semelhante, 
Redes de cooperação e estratégias de marketing no mercado internacional: entendendo a atuação de um consórcio de exportação e de uma associação de micro e pequenas empresas exportadoras.

sendo formadas a partir de características que permeiam o preço, produto, praça e promoção.

\section{LIMITAÇÕES E SUGESTÕES}

A impossibilidade de generalizar os resultados desta pesquisa não se caracteriza como uma limitação deste estudo por ele ser exploratório. Além disso, o método Grounded Theory não tem como objetivo generalizar as análises feitas a partir de um objeto de estudo.

A principal limitação deste estudo se encontra no fato de comparar organizações de segmentos diferentes. Entretanto, tal limitação é atenuada pelo fato dos pesquisadores buscarem redes já inseridas no mercado internacional e com experiência na área de marketing e que poderiam contribuir significativamente para tal estudo.

0 presente estudo apresenta implicações gerenciais e teóricas na abordagem das redes organizacionais na perspectiva das estratégias de marketing. Nas implicações gerenciais, destaca-se a necessidade de um planejamento efetivo de marketing a partir de pesquisas de marketing no mercado internacional. Do ponto de vista teórico, este estudo: (1) não supre por completo a lacuna de conhecimento na temática das redes interorganizacionais quando analisadas sob a persectiva do marketing, entretanto, inova ao fazer esta comparação; (2) lança insights a respeito da atuação dos consórcios e as formas jurídicas; e, (3) contribui para que a lacuna de conhecimento existente sobre este objeto de investigação seja atenuada.

Como sugestões para pesquisas futuras, se torna interessante que outros segmentos sejam analisados no intuito de refutar ou confirmar as análises presentes neste artigo, ampliando a teoria deste campo de investigação por meio de estudos empíricos, ou, até mesmo, verificar se a dinâmica de outros segmentos são parecidas. Hipóteses relacionadas ao desempenho exportador; à influência do marketing e do composto promocional no desempenho final de redes podem ser lançadas e testadas por pesquisadores que investiguem esta temática.

\section{REFERÊNCIAS}

ABBY, N. e SLATER, S. F. Management Influences on Export Performance: A Review of the Empirical Literature 1978-88. In: International Marketing Review, v. 6, no 4, 1989, p. 07-26.

CADOGAN, J. W., DIAMANTOPOULOS. A. e MORTANGES, C. P. de. A Measure of Export Market Orientation: Scale Development and Cross-cultural Validation. In: Journal of Internacional Bussiness Studies, v. 30, no 4, 1999, p. 689-707.

CAVUSGIL, T. S. e ZOU, S. Marketing Strategic-Performance Relationship: An Investigation of the Empirical Link in Export Market Ventures. In: Journal of Marketing, v. 58, jan. 1994, p. 01-21.

CRUZ, B. de P. A.; Fatores críticos de sucesso no mercado internacional: estudo comparativo das estratégias de marketing em um consórcio de exportação e em uma empresa não consorciada. 2004. 83 f. Trabalho de conclusão de curso (graduação) - Departamento de Administração e Economia da Universidade Federal de Lavras, Lavras, 2004.

e ZOUAIN, D. M. Atuação de Consórcios de Exportação Brasileiros no Segmento de Moda Praia. In: Encontro de Marketing da Anpad, 3, 2006, Rio de Janeiro - RJ. Anais do III EMA. Rio de Janeiro: ANAPAD, 2006, 1 CD-ROOM.

Quais contribuições na área de marketing um consórcio de exportação pode levar às micro e pequenas empresas do setor confecções do Nordeste? Propostas a partir do estudo do 
Pólo de Moda Íntima de Nova Friburgo (RJ). In: Seminário Internacional de Gestão da Inovação Tecnológica no Nordeste, 2, 2005, Fortaleza - CE. Anais do INOVA. Fortaleza: Federação das Indústrias do Estado do Ceará, 2005. 1 CD-ROM.

Estratégias de Marketing em Consórcios de Exportação: Formulação de Hipóteses a partir da Indústria Têxtil e de Confecções no Brasil. In: Seminário de Gestão de Negócios, 2, 2005, Curitiba - PR. Anais do II Seminário de Gestão de Negócios. Curitiba: UniFAE, 2005b. 1 CD-ROM.

GOULDING, C. Grounded theory: a magical formula or a potential nightmare? The Marketing Review, vol. 2, 2001, p. 21-34.

HARRIGAN, Strategic Alliances: Their New Role in Global Competition. In: Columbia Journal of World Business. Summer, 1983, p. 67-69.

KLOTZLE, M. C. e CAIRES, C. O desempenho exportador de micro, pequenas e médias empresas brasileiras. In: Encontro da ANPAD, 28., 2004, Curitiba. Anais do XXVIII ENANPAD. Curitiba: ANPAD, 2004. 1 CD-ROM.

MACERA, A. P. e URDAN, A. T. Orientação para o Mercado Externo: Teste de um modelo no Brasil e sua Aplicação a uma amostra de Empresas Exportadoras Brasileiras. In: Revista de Administração Contemporânea. Associação Nacional de Programas de Pós-Graduação em Administração. V. 8. n. 2, (abril/junho, 2004). Rio de Janeiro: ANPAD, 2004 - trimestral.

MACADAR, B. M. de. A experiência exportadora da Associação dos Fabricantes de Estofados e Móveis Complementares. In: VERSCHOORE, J. R. de S (org). Redes de Cooperação: uma nova organização de pequenas e médias empresas no Rio Grande do Sul. Porto Alegre: FEE, 2004.

MINERVINI, N. O exportador. Makron Books, São Paulo, 2001.

RAMOS, P. M., MAYA, P. C. Da C. E BORNIA, A. C. Um Estudo Científico do Componete Preço e sua Relação com o Marketing Mix de Produto Brasileiro de Exportação: uma Pesquisa Multicasos nas Empresas do Consórcio de Exportação de Calçados de São João Batista / Santa Catarina. In: Encontro da ANPAD, 29., 2005, Curitiba. Anais do XXIX ENANPAD. Brasília: ANPAD, 2005. 1 CD-ROM.

ROSENFELD, S. A. Brinding business clusters into the mainstream of economic development. In: European Planning Studies. Abingdon, Carfax, v. 5, n. 1, 1997.

VERSCHOORE, J. R. de S. Redes de Cooperação: concepções teóricas e verificações empíricas. In: VERSCHOORE, J. R. de S (org). Redes de Cooperação: uma nova organização de pequenas e médias empresas no Rio Grande do Sul. Porto Alegre: FEE, 2004.

VIEIRA, M. M. F. Por uma boa pesquisa (qualitativa) em administração. In: VIEIRA, M. M. F. e ZOUAIN, D. M. (orgs). Pesquisa Qualitativa em Administração. Rio de Janeiro: FGV, 2004.

WIND, Y. e ROBERTSON, T. S. Marketing Strategy: New Directions for Theory and Reserarch. In: Journal of Marketing, v. 47, 1983, p. 12-25. 